\title{
MICROSTRUCTURAL UNDERSTANDING \\ AND \\ CRITICAL CURRENT OPTIMIZATION \\ OF \\ ADVANCED HIGH FIELD SUPERCONDUCTORS
}

\author{
Progress Report \\ for contract \\ NO. DE-FG02-86ER52131 \\ David C. Larbalestier \\ Principal Investigator \\ Applied Superconductivity Center \\ University of Wisconsin-Madison \\ Report by \\ L.A. Bonney, T.C. Willis, and D.C. Larbalestier
}

February 1, 1991 - March 31, 1993

Prepared for

THE US DEPARTMENT OF ENERGY

\section{MASTER}

DIBTRIBUTION OF THIS DOCUMENT .S UNLIMTED

\section{NOTICE}

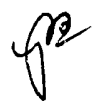

This report was prepared as an account of work sponsored by the United States Government. Neither the United States nor the Department of Energy, nor any of their employees, makes any varranty, express or implied, or assumes any legal liability or responsibility for the accuracy, completeness, or usefulness of any information, apparatus, product or process disclosed or represents that its use would not infringe privately-owned rights. 
I. $\quad \mathrm{Nb}_{\mathbf{3}} \mathrm{Sn}$

It is of great importance to improve critical current density, $J_{c}$, in A15 superconductors for high field magnet applications. Most current work to improve $J_{c}$ in A15 wires concentrates on increasing the overall $J_{c}$ by increasing the fraction of superconducting phase in the wire, by improving the uniformity of the superconductor cross section along the length of the wire and by adjusting the strain state of the A15 layer. The goal of the A15 work in this group was to investigate the intrinsic $J_{c}$ of the A15 layer itself. To do this, a better understanding of factors controlling the intrinsic $J_{c}$ of the $\mathrm{Nb}_{3} \mathrm{Sn}$ was pursued. It is well established that A15 $J_{c}$ is linked to grain size ${ }^{1}$ and thus that grain boundaries are flux pinning sites in these superconductors. ${ }^{2}$ Flux pinning theory suggests that grain boundary chemistry could affect the strength of flux pinning and consequently $J_{c}$. Grain boundary composition affects the impurity parameter, $\alpha$, and thus the elemental pinning force $\left(f_{p}\right)$ of the grain boundary. ${ }^{3}$ Scanlan, et $a{ }^{2},{ }^{2}$ found that the A15 layer $J_{c}$ of bronze-processed composite wires was $20 \%$ lower than that of $\mathrm{Nb}$-Sn tapes of similar grain size. Whether differences in $J_{c}$ were due to differences in strain in the A15 layer or differences in layer composition produced by the presence or absence of copper is unclear. Copper is known to reside in the grain boundaries of $\mathrm{Nb}_{3} \mathrm{Sn}$ formed in the presence of $\mathrm{Cu}^{4}{ }^{4}$ as is the case for all filamentary $\mathrm{Nb}_{3} \mathrm{Sn}$ conductors. In this work we began experiments to systematically test whether grain boundary composition does affect $J_{c}$.

The material chosen for these experiments was a binary diffusion couple of niobium and tin. Starting samples were of nominally constant grain size, bulk composition and lattice strain. Copper was electroplated onto these $\mathrm{Nb}$-Sn tapes and both $\mathrm{Cu}$-plated and $\mathrm{Cu}$-free tapes were annealed at $600^{\circ} \mathrm{C}$ in order to diffuse $\mathrm{Cu}$ into the grain boundaries in the former case and to 
have a control sample of similar treatment in the latter case. Magnetization in applied magnetic fields between 0 and $12 \mathrm{~T}$ was measured for the untreated, as-received, tape and for the $\mathrm{Cu}$-free heat treated and $\mathrm{Cu}$-plated and heat treated tape. Magnetization measurements were made by vibrating sample magnetometry (VSM) with the applied field normal to the plane of the $\mathrm{Nb}_{3} \mathrm{Sn}$ layer as shown in Figure 1. Magnetization $\mathrm{J}_{\mathrm{c}}$ is shown in Figure 2 for the untreated tape, in Figure 3 for the $\mathrm{Cu}$-treated tape and in Figure 4 for the $\mathrm{Cu}$-free treated tape.

Although $B_{c 2}$ values of the treated tapes were depressed, $J_{c}$ of the Cu-treated samples exceeded that of some, but not all, untreated samples and exceeded that of the Cu-free treated samples by a factor of three. Unfortunately, results for each treatment were scattered. Microstructural analysis by scanning electron microscopy (SEM) showed that the $\mathrm{Nb}_{3} \mathrm{Sn}$ layers of these tapes were not always continuc'ss and were not of uniform thickness. More uniform samples are needed for such experiments to be conclusive, but these results suggest that grain boundary copper enhances the $\mathrm{J}_{c}$ of $\mathrm{Nb}_{3} \mathrm{Sn}$. Addition of other elements to the grain boundaries of A15 compounds might further enhance $J_{c}$, but no such study is presently planned.

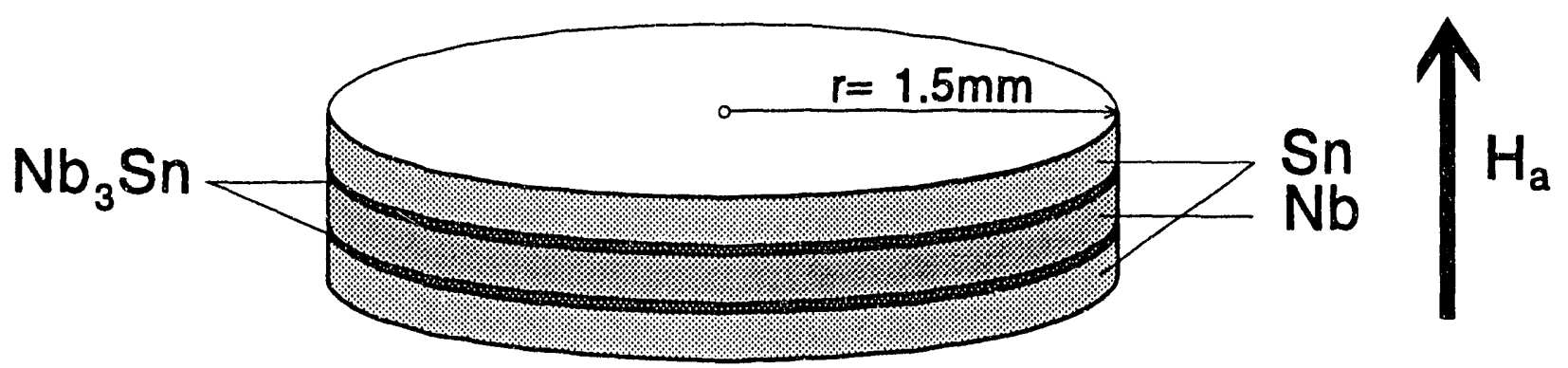

Figure 1 Sample geometry for magnetization measurements. 


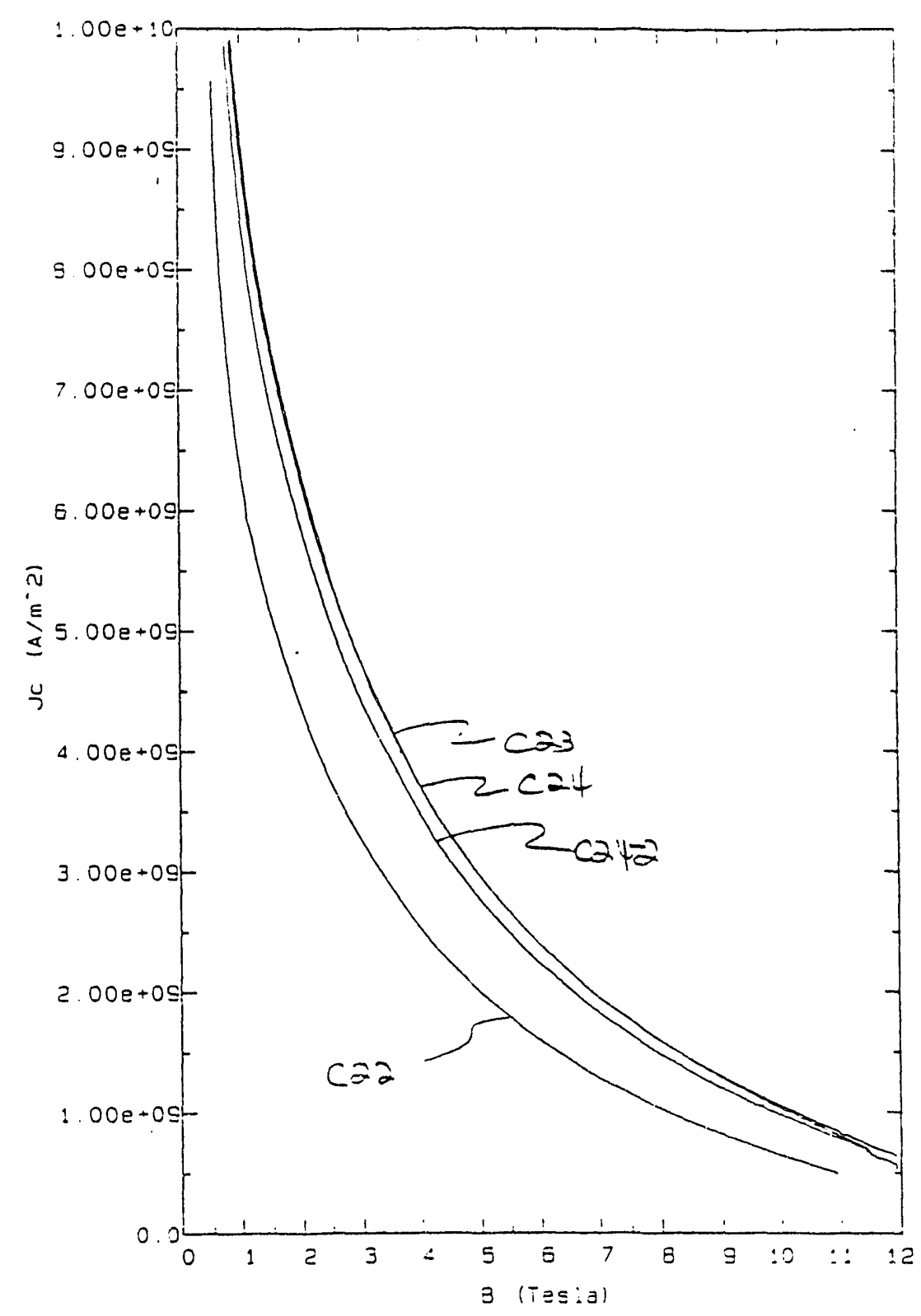

Figure 2 Repeated measurements of magnetization $J_{c}$ versus applied field for the untreated $\mathrm{Nb}-\mathrm{Sn}$ tape at $4.2 \mathrm{~K}$ 


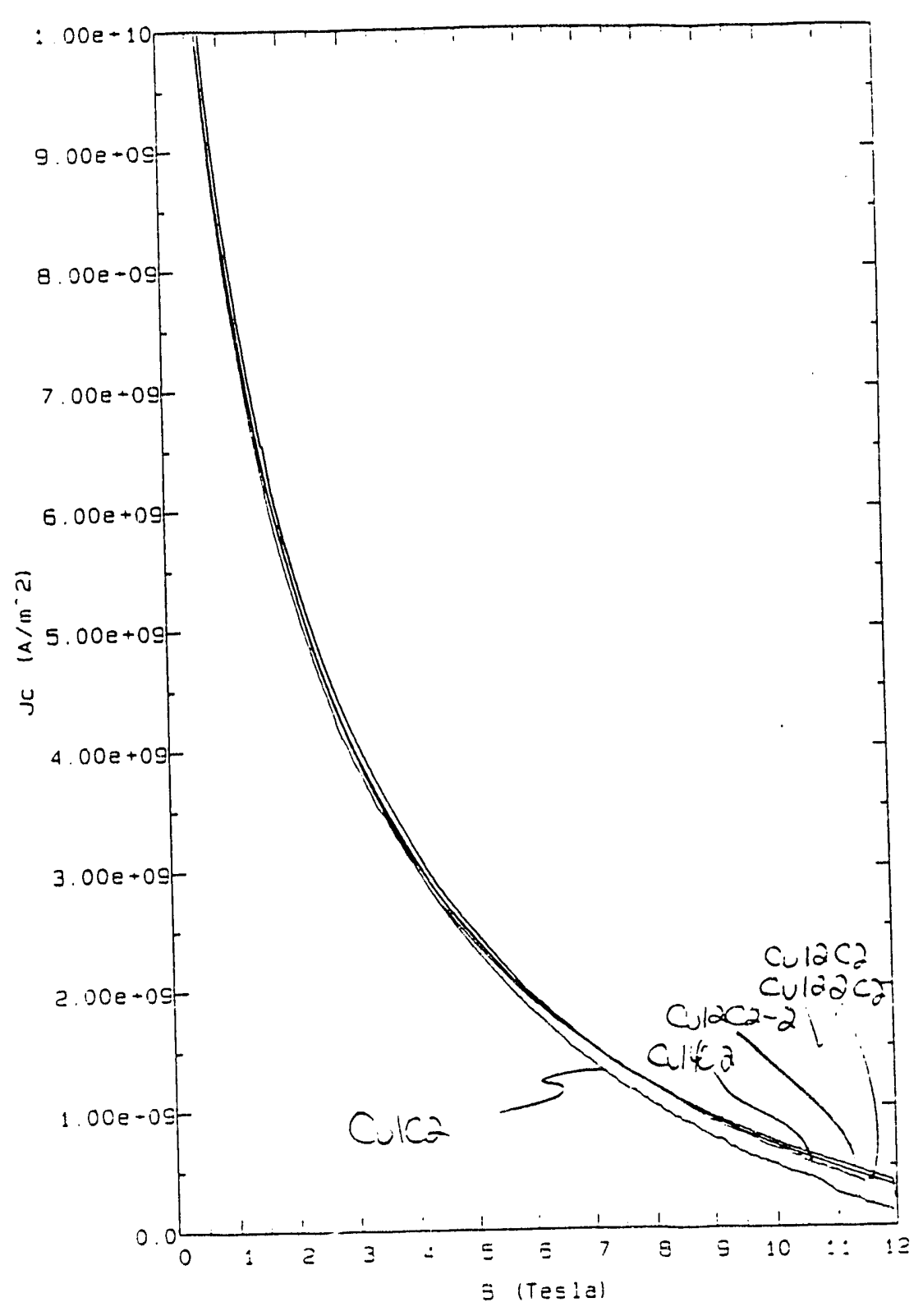

Figure 3 Repeated measurements of magnetization $J_{c}$ versus applied field for the copper treated $\mathrm{Nb}-\mathrm{Sn}$ tape at $4.2 \mathrm{~K}$. 


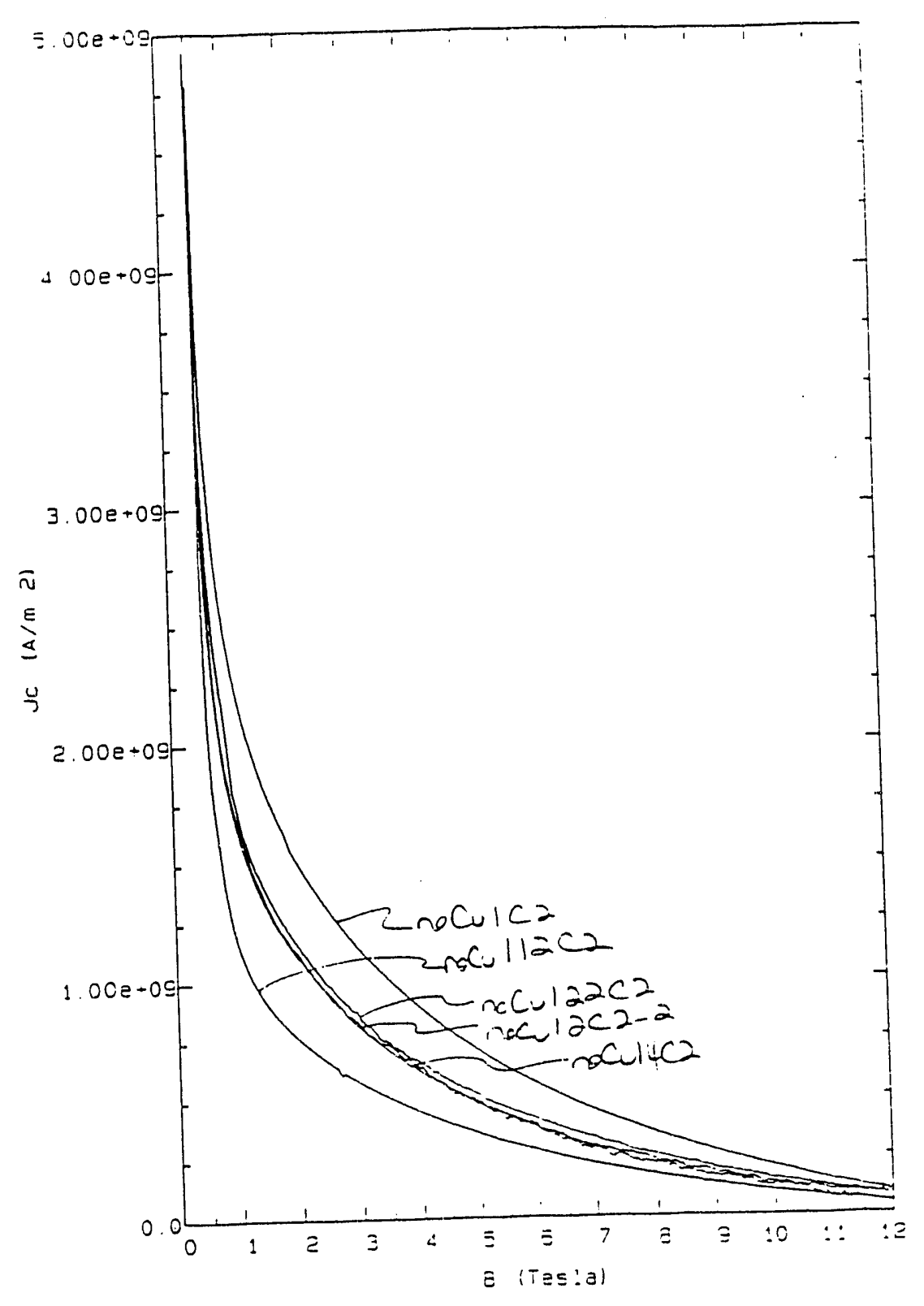

Figure 4 Repeated measurements of magnetization $J_{c}$ versus field for the copper-free treated $\mathrm{Nb}-\mathrm{Sn}$ tape at $4.2 \mathrm{~K}$. 


\section{CHEVREL PHASE}

In September 1991 a large fraction of the Chevrel Phase research community met in Geneva in order to review the status of Chevrel Phase applications and basic science. This workshop was hosted by Øysten Fischer and Michel Decroux of the University of Geneva, and Darid Larbalestier was the US organizer. The central issues for high field and high current density applications are those of electromagnetic granularity at powder particle or grain boundaries and insufficient flux pinning. Both these issues were discussed extensively at the workshop and the collective opinions of the workshop participants were summarized by Larbalestier ${ }^{5}$ in a final summary.

The Wisconsin group concentrated first on the granularity issue, since this produced the lower limit to the $J_{c}$. The principal results of this work are:

(i) Work on Mo-sheathed $\mathrm{PbMo}_{6} \mathrm{~S}_{8}$ (PMS) wires showed that they do not densify properly unless they are hot isostatically pressed (HIP), as shown in Figure $5 .^{6}$ Without a HIP treatment, the $I_{c}$ is independent of whether $H$ is parallel to or normal to $I_{c}$, as shown in Figure 6. We interpret this as evidence that the current flows in a locally, percolative fashion, according to whatever path provides the best local connection. Only when densified by HIP'ing, does $I_{c}(\| H)$ greatly exceed $I_{c}(\perp H)$ (Figure 7). 

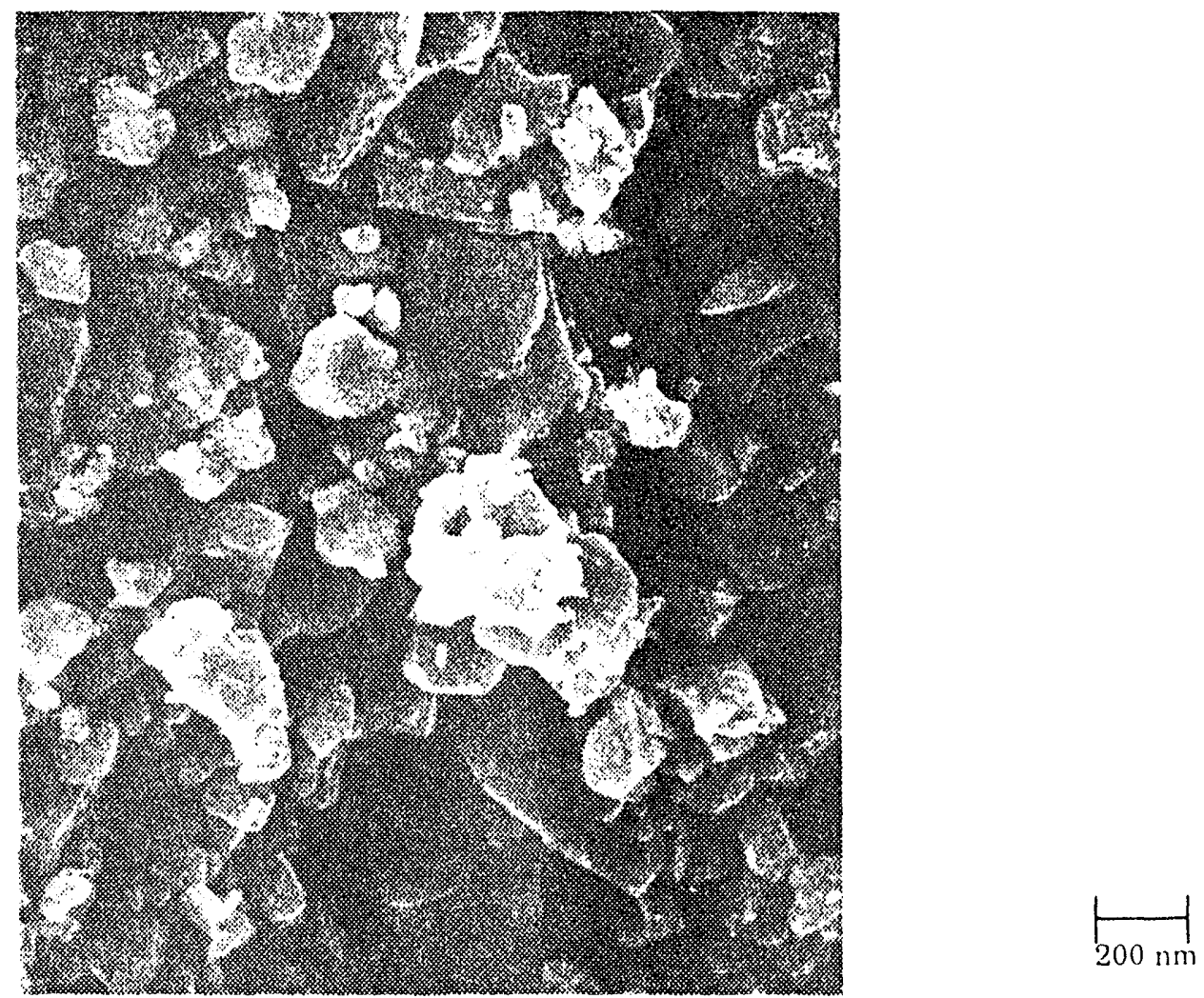

Figure 5 High-resolution scanning electron microscope micrograph of the fractured surface of conventionally sintered $\mathrm{Pb}_{1.0} \mathrm{Mo}_{6} \mathrm{~S}_{7.5}$ wire heat treated at $700{ }^{\circ} \mathrm{C}$ for $24 \mathrm{hr}^{6}$

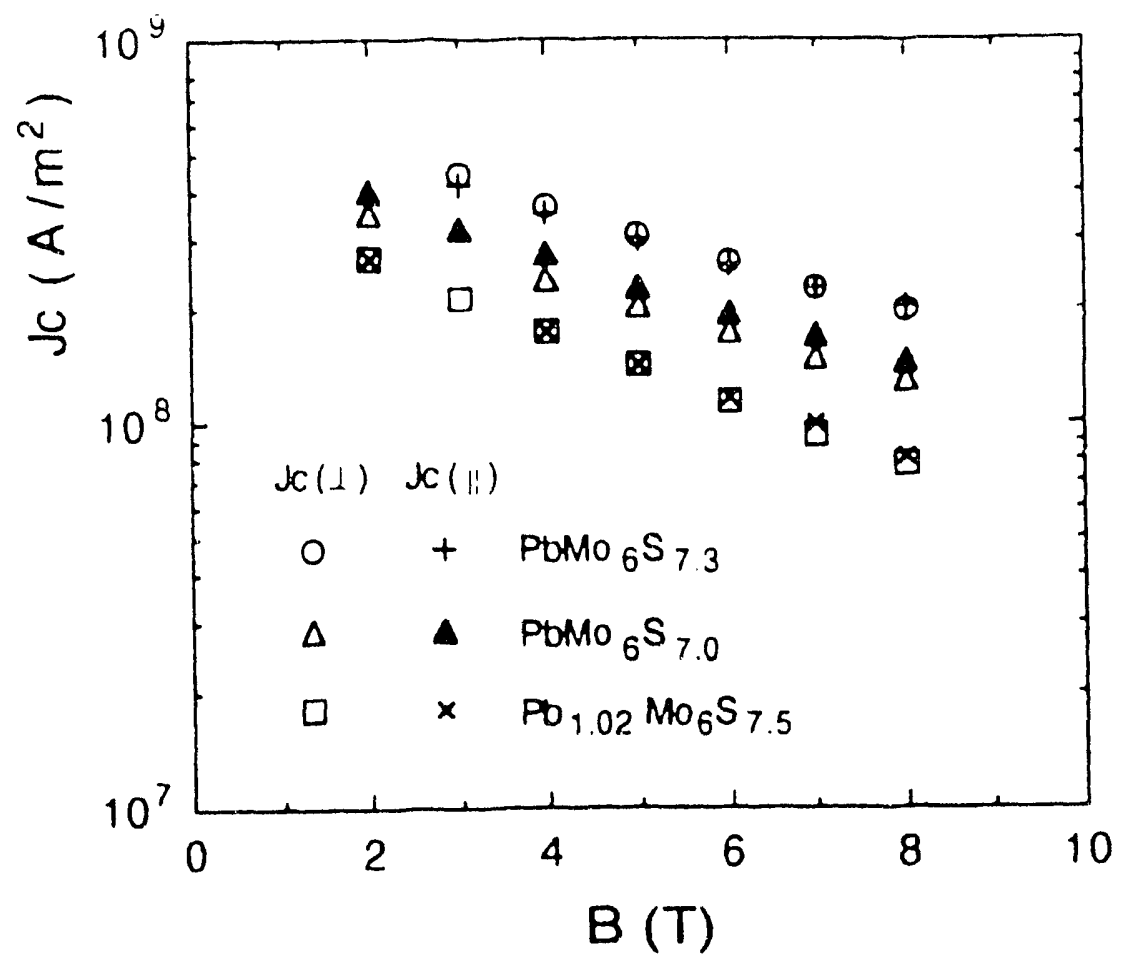

Figure 6 Comparison of $J_{c}(\|)$ and $J_{c}(\perp)$ data for conventionally sintered $\mathrm{PbMo}_{6} \mathrm{~S}_{7.3}$, $\mathrm{PbMo}_{6} \mathrm{~S}_{7,0}$, and $\mathrm{Pb}_{1,02} \mathrm{Mo}_{6} \mathrm{~S}_{7.5}$ wires. ${ }^{6}$ 


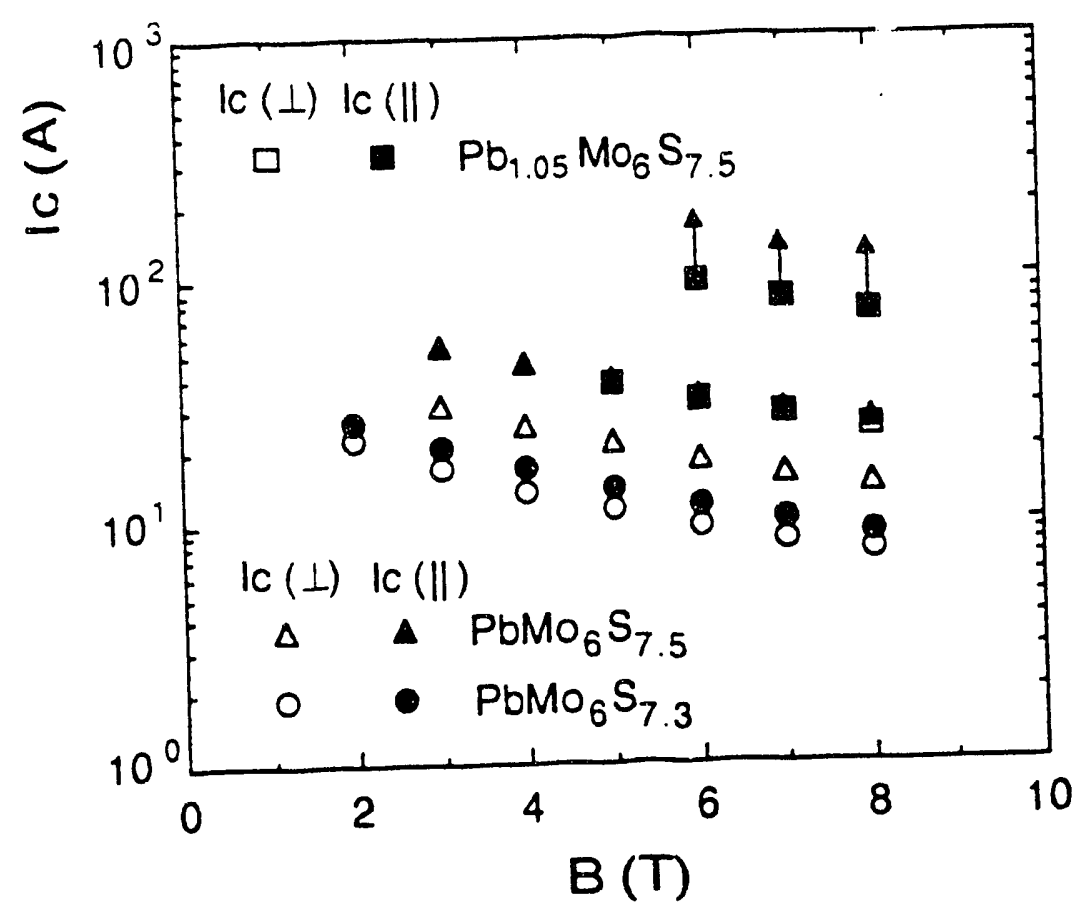

Figure 7 Typical $I_{c}(\|) / I_{c}(\perp)$ data for straight PMS wires HIP treated at $1200^{\circ} \mathrm{C} .^{6}$

(ii) An additional test of this hypothesis was performed in a set of experiments by Le Lay et $\mathrm{al}_{,}^{7,8}$ on HIP'ed and non-HIP'ed powder samples of mixed and pure $\mathrm{Pb}$ - and $\mathrm{Sn}$ Chevrel phases (PMS and SMS). As in the Mo-sheathed wires, these samples did not densify without HIP'ing. Figure 8 compares the densified and percolative microstructures of typical of bulk Chevrel phase HIP'ed and non-HIP'ed samples, respectively. ${ }^{8}$ In the HIP'ed samples, we found perfect size scaling of the magnetization, which indicates complete connectivity (Figure 9). This perfect size scaling, however, was absent from the non-HIP'ed samples. In addition, reduced pinning force curves $\left(F_{p} / F_{p_{\max }}\right.$ versus $\left.b^{\dagger}\right)$ show a $F_{p} / F_{p_{\max }} \propto b^{1 / 2}(1 \cdot b)^{2}$ behavior typical of the grain boundary pinning mechanism found in $\mathrm{Nb}_{3} \mathrm{Sn}$ (Figure 10). ${ }^{8}$

$+b=B / B^{*}$, where $B^{*}$ is the field at which the magnetization hysteresis, $\Delta M$, becomes zero. 

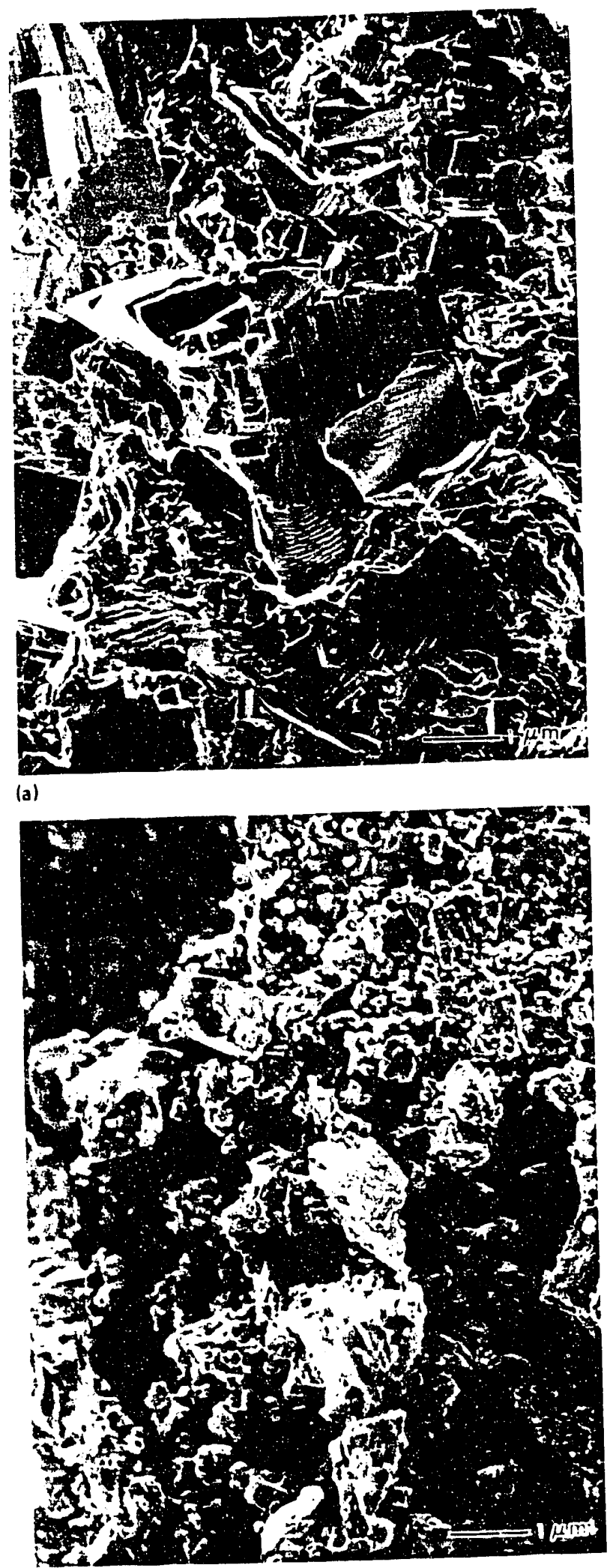

(b)

Figure 8 High-resolution SEM images of (a) $\mathrm{Sn}_{1} \mathrm{Mo}_{6} \mathrm{~S}_{7.6}$ HIP'ed and (b) $\mathrm{Pb}_{0.1} \mathrm{Sn}_{0.9} \mathrm{Mo}_{6} \mathrm{~S}_{7.6}$ non-HIP'ed bulk samples made at $800^{\circ} \mathrm{C}^{8}$ 


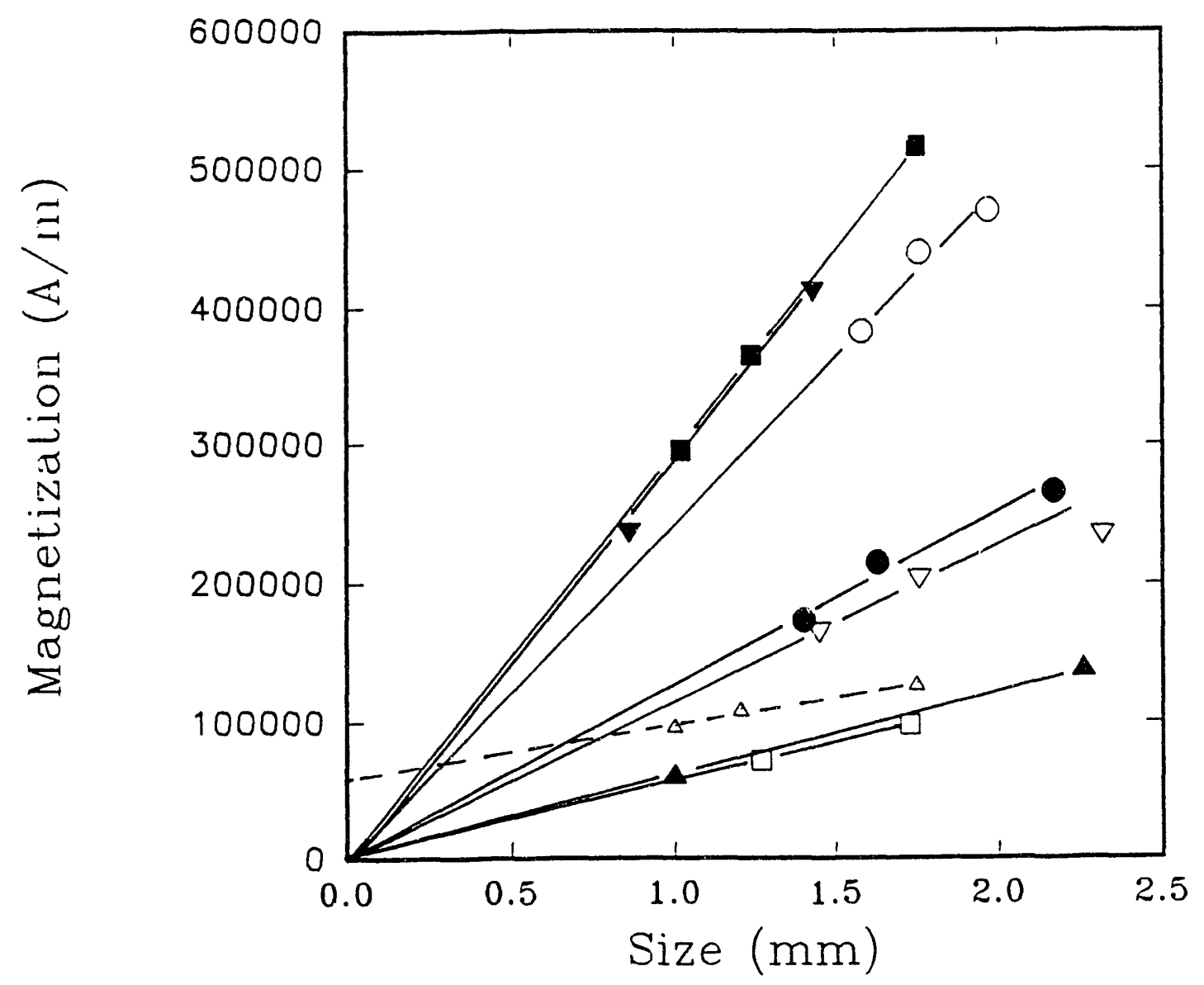

Figure 9 Magnetization as a function of sample size for various $\mathrm{Pb}_{\mathbf{x}} \mathrm{Sn}_{1 \cdot \mathbf{x}} \mathrm{Mo}_{6} \mathrm{~S}_{7.6}$ samples at $4.2 \mathrm{~K}$.

- HIP'ed at $800^{\circ} \mathrm{C}: \nabla x=1 ; \square x=0.5 ; \square x=0.1 ; \nabla x=0$

- HIP'ed at $900^{\circ} \mathrm{C}: 0 x=1 ; \Delta x=0.1 ; \bigcirc x=0$

- non-HIP'ed $\left(1100^{\circ} \mathrm{C}\right): \Delta x=0.5$ 


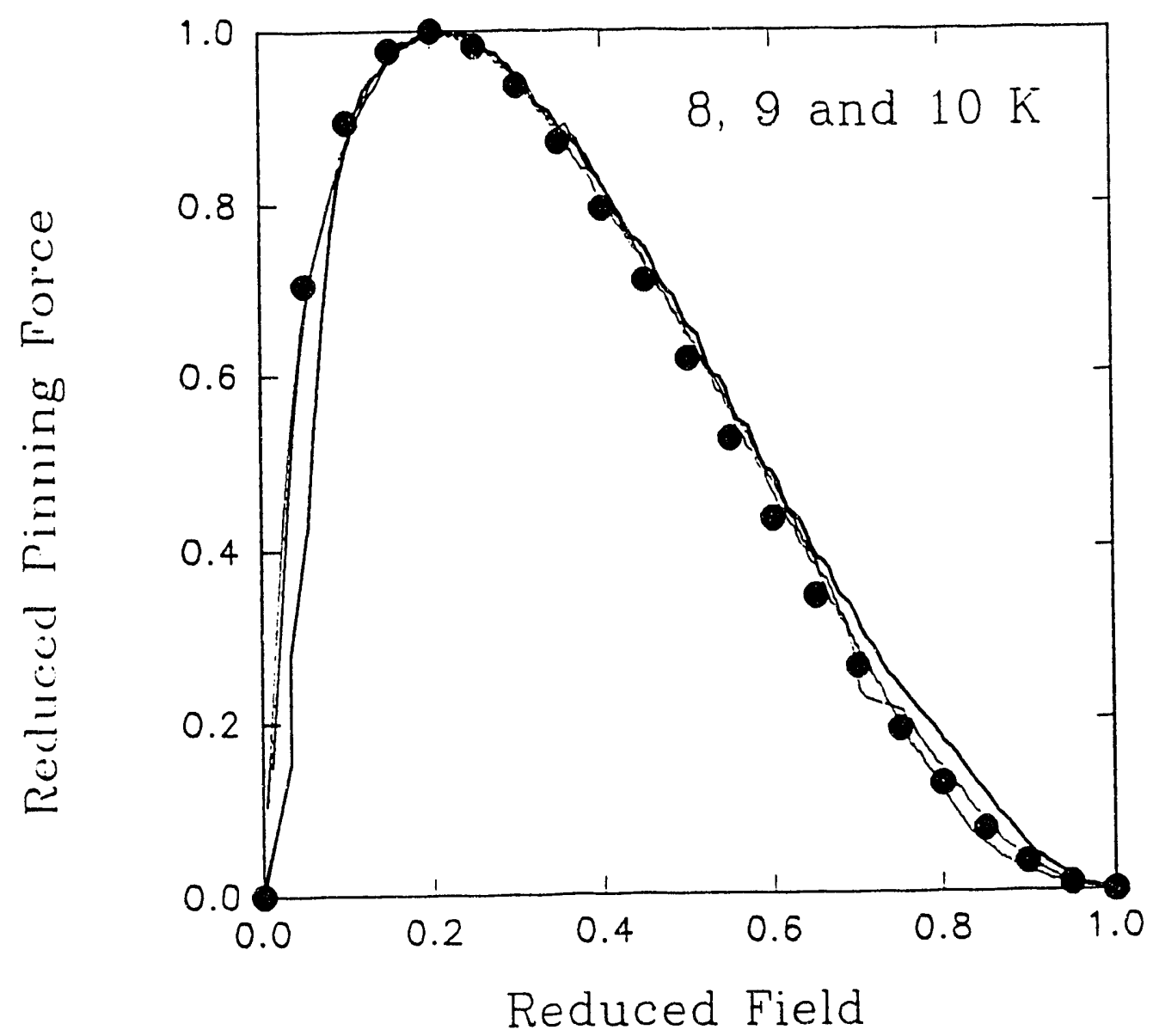

Figure 10 Reduced pinning force as a function of reduced critical field for a $\mathrm{Pb}_{0.1} \mathrm{Sn}_{0.9} \mathrm{Mo}_{6} \mathrm{~S}_{7.6}$ bulk sample $\left(800^{\circ} \mathrm{C} \mathrm{HIP}\right) . \quad=$ points calculated using $F_{p} / F_{p_{\max }}=C\left[b^{i / 2}(1-b)^{2}\right]$. $^{8}$

These results are conceptually important because they make it clear that there is no intrinsic granularity to Chevrel Phases. ${ }^{\dagger t}$ The problem is rather one of grain-to-grain connectivity, which is a problem that can be solved by appropriate processing, in particular by the use of the HIP. Thus, the next step was to tackle the second important issue winich is that of flux pinning. To address this problem Le Lay grew some single crystals of $\mathrm{SnMo}_{6} \mathrm{~S}_{8}$ and measured their magnetization. ${ }^{3}$ The most-studied crystal was tin-deficient and had a composition of $\mathrm{Sn}_{0.854} \mathrm{Mo}_{6} \mathrm{~S}_{8} \cdot{ }^{10}$ The principal results of this study are:

${ }^{+1}$ This point was persuasively argued by Deutscher at the Geneva workshop. 
- (a) " Single crystals, which contained defects that could act as pinning sites, do have measurable flux pinning. Despite the high defect density, however, the flux pinning in these sirigle crystals is about a factor of 5 less than observed in polycrystalline SMS $\left(\sim 150 \mathrm{~A} / \mathrm{mm}^{2}\right.$ versus $750 \mathrm{~A} / \mathrm{mm}^{2}$ at $\left.10 \mathrm{~T}\right)($ Figure 11$){ }^{9}$

(b) The implication of tr ase results is that the way to high $\mathrm{J}_{c}$ is to refine the grain size thus ensuring a high density of grain boundary flux pinning sites and to fully densify the material so that there is no connectivity problem.

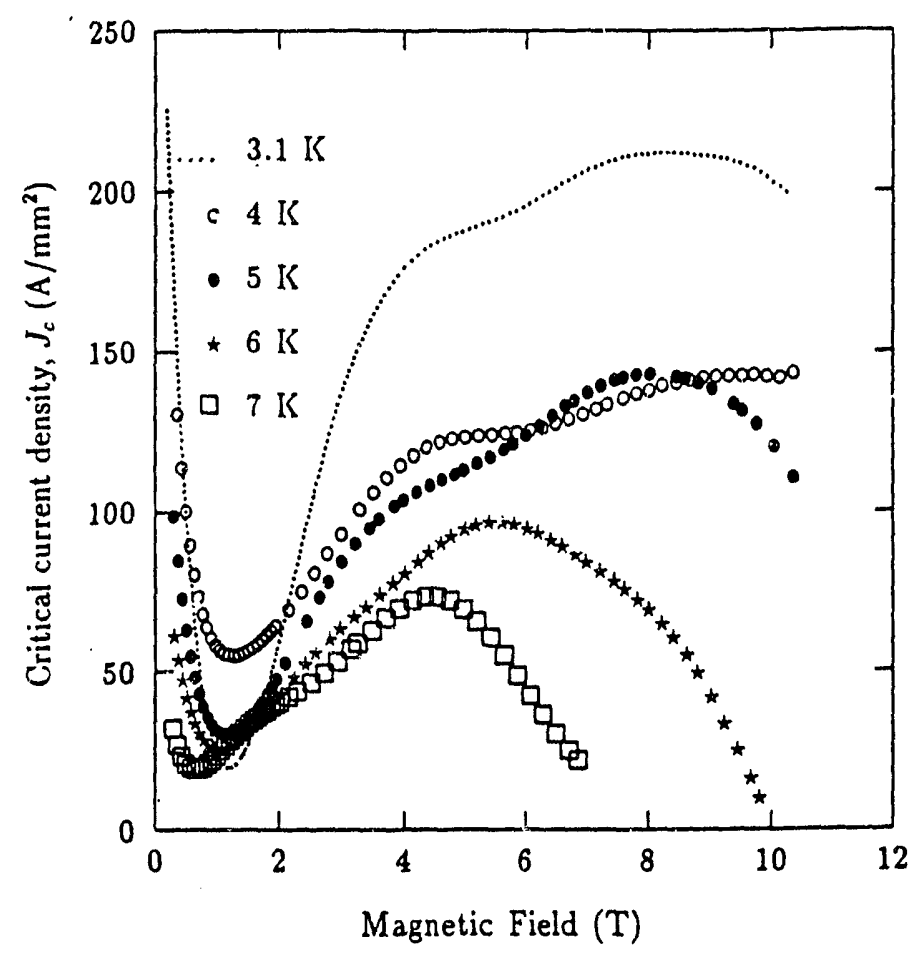

Figure 11 Magnetization critical current densities of $\mathrm{SnMo}_{6} \mathrm{~S}_{8}$ single crystal at several temperatures.? 
. To test whether grain size refinement is the key to higher $J_{c}$ in Chevrel Phase materials, Bonney has been performing experiments which compare grain size and $\mathrm{J}_{c}$ in $\mathrm{SnMo}_{6} \mathrm{~S}_{8}{ }^{11}$ Results indicate that $J_{c}$ is proportional to grain boundary length per unit area at lower fields (Figure 12). Thus, microstructure refinement is important to $\mathrm{J}_{\mathrm{c}}$ enhancement. Bonney has begun experiments to characterize high field $J_{c}$ dependencies in $\mathrm{SnMo}_{6} \mathrm{~S}_{8} . J_{c}$ has been measured by vibrating sample magnetometry (VSM) up to 30 Tesla at MIT's Bitter Magnet Laboratory. Further microstructural analysis by transmission electron microscopy is being performed.

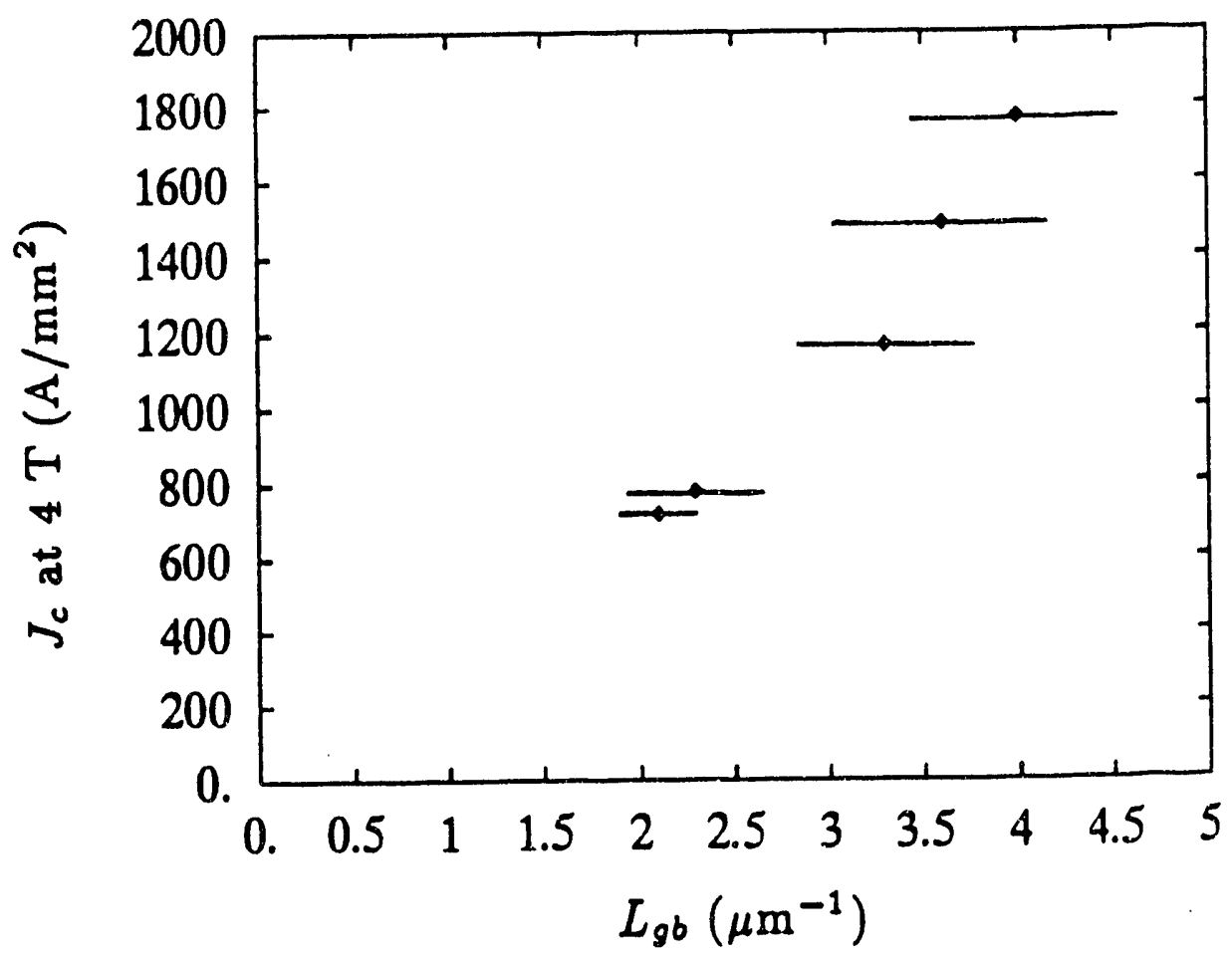

Figure $12 \mathrm{~J}_{\mathrm{c}}$ dependence on grain boundary line length per unit area, $\mathrm{L}_{\mathrm{gb}}$. 
- These results have therefore clearly indicated the future direction of Chevrel phase superconductor development. A benefit of the Geneva Workshop was that we were able to learn how to make oxygen-free materials from Dave Hinks. Bonney and Willis have replicated this process and in their latest samples (which were reported in Willis' talk at the 1992 Berkeley Low Temperature Materials Workshop) they have achieved $J_{c}$ and $T_{c}$ values equivalent to the best yet reported (Figure 13).

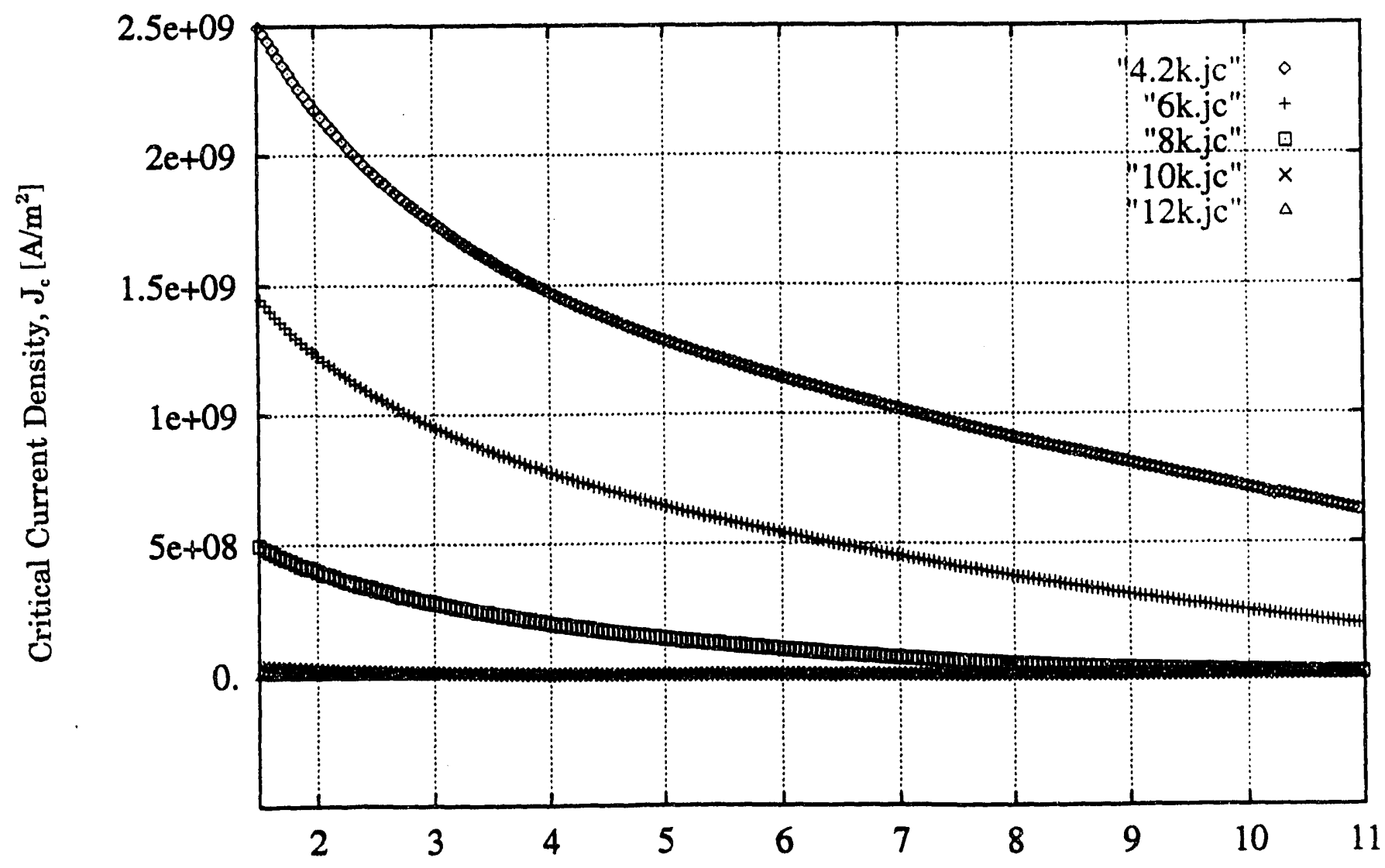

Field B [Tesla]

Figure 13 Critical current densities of HIPped $\mathrm{Pb}_{0.8} \mathrm{Sn}_{0.2} \mathrm{Mo}_{6} \mathrm{~S}_{8}$ sample prepared at UW, measured at temperatures of $4.2,6,8,10$, and $12 \mathrm{~K}$. 


\section{REFERENCES}

1. J.J. Hanak and R.E. Enstrom, "Flux pinning in $\mathrm{Nb}_{3} \mathrm{Sn}$ by grain boundaries," Proc. 10th Int. Conf. Low Temp. Phys. (1966) S94.

2. R.M. Scanlan, W.A. Fietz, and E.F. Koch, "Flux pinning centers in superconducting $\mathrm{Nb}_{3} \mathrm{Sn}, "$ J. Appl. Phys. 46:5 (1975) 2244-2249.

3. W.E. Yetter, D.A. Thomas and E.J. Kramer, "Flux pinning by thin planar defects," Philos. Mag. B46, 523 (1982). W.E. Yetter and E.J. Kramer; J. Mater. Sci. 17 (1982) 2992.

4. M. Suenaga and W. Jansen, "Chemical compositions at and near the grain boundaries in bronze-processed superconducting $\mathrm{Nb}_{3} \mathrm{Sn}$," Appl. Phys. Lett. 43:8 (1983) 791-793.

5. D.C. Larbalestier, "Summary on the session, microstructure, interface properties, granularity, and critical current issues for chevrel phase superconductors," Proceedings of the International Workshop on Chevrel Phase Superconductors, ed. M. Decroux, pp. 77-78, 1991.

6. H. Yamasaki, M. Umeda, S. Kosaka, Y. Kimura, T. C. Willis and D. C. Larbalestier, "Poor intergrain connectivity of $\mathrm{PbMo}_{6} \mathrm{~S}_{8}$ in sintered Mo-sheathed wires and the beneficial effect of hot-isostatic treatments on the transport critical current density," J. Appl. Phys., vol. 20 (3), pp 1606-1613, 1991.

7. L. Le Lay, T.C. Willis, and D.C. Larbalestier, "Fully connected $\mathrm{Pb}_{1 \cdot \mathrm{x}} \mathrm{Sn}_{\mathbf{x}} \mathrm{Mo}_{6} \mathrm{~S}_{8}$ bulk sample made by hot isostatic pressing," Proceedings of the International Workshop on Chevrel Phase Superconductors, ed. M. Decroux, pp. 43-44, 1991.

8. L. Le Lay, T.C. Willis, and D.C. Larbalestier, "Fully connected bulk $\mathrm{Pb}_{1 . x} \mathrm{Sn}_{\mathbf{x}} \mathrm{Mo}_{6} \mathrm{~S}_{7.6}$ samples made by hot isostatic pressing," Appl. Phys. Lett. Vol. 60:6, pps: 775-777, 1992.

9. L. Le Lay, T.C. Wilis, and D..C.Larbalestier, "Magnetization properties of a $\mathrm{SnMo}_{6} \mathrm{~S}_{8}$ single crystal," IEEE Transactions on Magnetics, Vol. 27:2, pp. 954-957, 1991.

10. L. LeLay, D. Powell, and T.C. Willis, "Structure of $\mathrm{Sn}_{0.854} \mathrm{Mo}_{6} \mathrm{~S}_{8}$," Acta Crystallographica, vol. C48, pp. 1179-1182, 1992.

11. L.A. Bonney, T.C. Willis, and D.C. Larbalestier, "Grain Size Dependence of Critical Current Densities in Hot Isostatically pressed $\mathrm{SnMo}_{6} \mathrm{~S}_{8}$, "IEEE Transactions on Applied Superconductivity, vol. 3, 1993. 


\section{PUBLICATIONS}

L.A. Bonney, T.C. Willis, and D.C. Larbalestier, "Grain Size Dependence of Critical Current Densities in Hot Isostatically Pressed $\mathrm{SnMo}_{6} \mathrm{~S}_{8 \text { ", }}$ IEEE Transactions on Applied Superconductivity, $\underline{3}, 1993$.

D.C. Larbalestier, "Summary on the session, microstructure, interface properties, granularity, and critical current issues for chevrel phase superconductors," Proceedings of the International Workshop on Chevrel Phase Superconductors, ed. M. Decroux, pp. 77-78, 1991.

L. Le Lay, D. Powell and T. C. Willis, "Structure of $\mathrm{Sn}_{0.854} \mathrm{Mo}_{6} \mathrm{~S}_{8}$," Acta Crystallographica, vol. C48, pp.1179-1182, 1992.

L. Le Lay, T.C. Willis, and D.C. Larbalestier, "Fully connected bulk $\mathrm{Pb}_{1-\mathrm{x}} \mathrm{Sn}_{\mathbf{x}} \mathrm{Mo}_{6} \mathrm{~S}_{7.6}$ samples made by hot isostatic pressing," Appl. Phys. Lett. vol. 60:6, pp. 775-777, 1992.

L. Le Lay, T.C. Willis, and D.C. Larbalestier, "Fully connected $\mathrm{Pb}_{1-x} \mathrm{Sn}_{\mathbf{x}} \mathrm{Mo}_{6} \mathrm{~S}_{8}$ bulk sample made by hot isostatic pressing," Proceedings of the International Workshop on Chevrel Phase Superconductors, ed. M. Decroux, pp. 43-44, 1991.

L. Le Lay, T.C. Wilis, and D..C.Larbalestier, "Magnetization properties of a $\mathrm{SnMo}_{6} \mathrm{~S}_{8}$ single crystal," IEEE Transactions on Magnetics, Vol. 27:2, pp. 954-957, 1991.

T.C. Willis, L. Le Lay, and D.C. Larbalestier, "Preparation and characterization of bulk samples of $\mathrm{Pb}_{1-\mathrm{x}} \mathrm{Sn}_{\mathrm{x}} \mathrm{Mo}_{6} \mathrm{~S}_{8}$," Proceedings of the International Workshop on Chevrel Phase Superconductors, ed. M. Decroux, p. 39, 1991.

H. Yamasaki, M. Umeda, S. Kosaka, Y. Kimura, T. C. Willis and D. C. Larbalestier, "Poor intergrain connectivity of $\mathrm{PbMo}_{6} \mathrm{~S}_{8}$ in sintered Mo-sheathed wires and the beneficial effect of hot-isostatic treatments on the transport critical current density, J. Appl. Phys., vol. 20:3, pp. 1606-1613, 1991. 

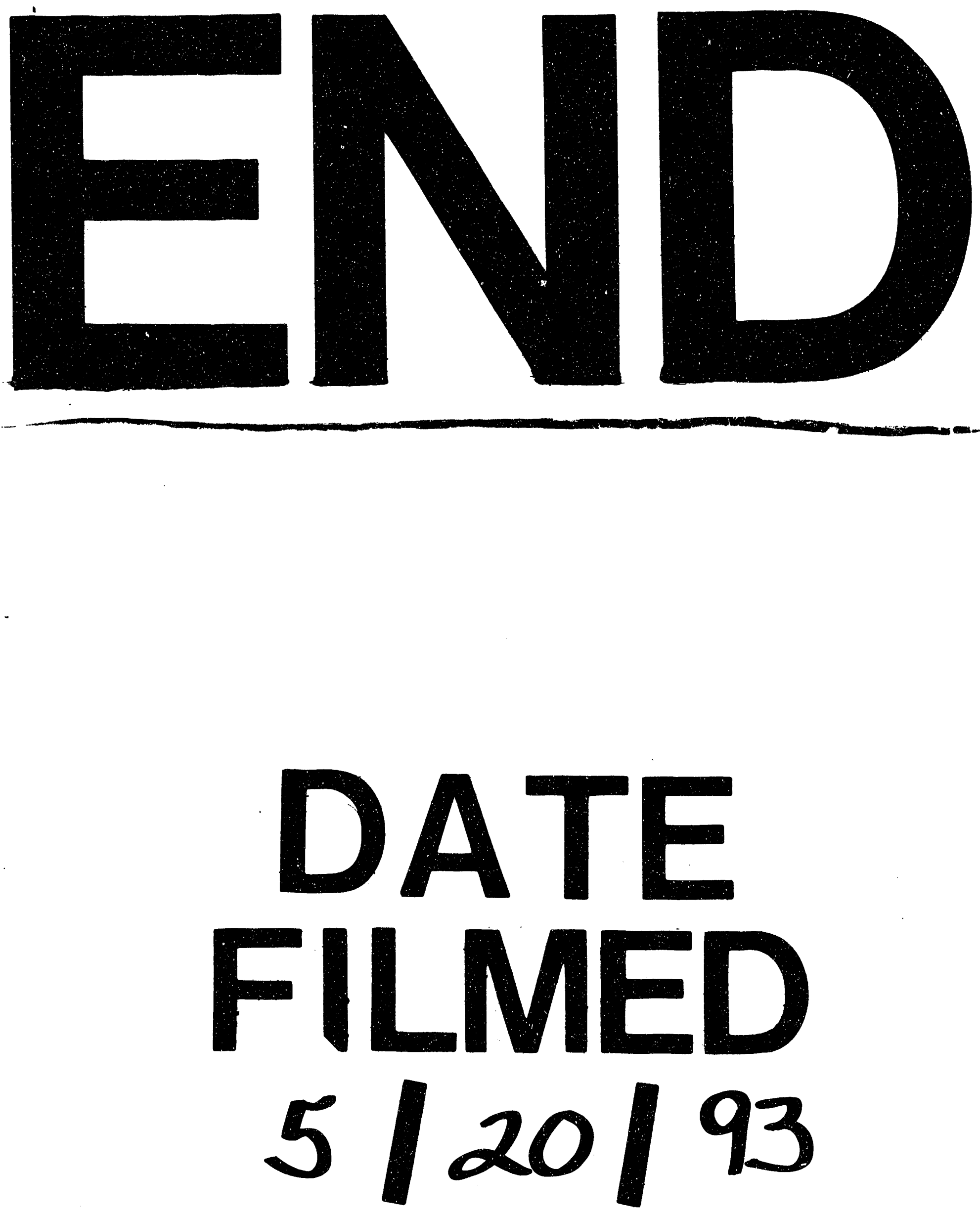
1 